\title{
EDUCAÇÃO AMBIENTAL: APLICAÇÃO DO PRINCÍPIO DOS "3R'sul" NO RESÍDUO SÓLIDO A PARTIR DE UM NÚCLEO AMBIENTAL
}

\author{
Ana Maria Geller ${ }^{1}$ \\ Jeferson Scheibler² \\ Claudia Wollmann Carvalho ${ }^{3}$ \\ Ismael de Lima ${ }^{4}$ \\ William Junior Sperb 5 \\ Wemerson de Castro Oliveira ${ }^{6}$
}

Resumo: Na escola temos a possibilidade de envolver a Educação Ambiental interdisciplinarmente, procurando conscientizar, de forma crítica e transformadora, a comunidade, interferindo nos hábitos para além de seus muros. Este trabalho retrata as ações desenvolvidas, durante dois anos, numa escola técnica, com estudantes do ensino médio, a partir do Núcleo de Gestão Ambiental Integrada. As ações perpassaram palestras, campanhas de sensibilização, separação de resíduos, horta, confecção de sabão e o agir na comunidade, introduzindo, também, aspectos da metodologia científica. Somente através da conscientização poderemos desenvolver uma cultura ambiental e sustentável, em que a qualidade de vida pode prevalecer, garantindo o futuro para a atual e próximas gerações.

Palavras-chave: Escola; Conscientização; Ação; Meio Ambiente.

${ }^{1}$ Instituto Federal Sul-rio-grandense -Campus Lajeado. Email: anageller@ifsul.edu.br. Link para o Lattes: http://lattes.cnpq.br/1351650500185318;

2 Instituto Federal Sul-rio-grandense -Campus Lajeado. Email: jefersonscheibler.lj213@academico.ifsul.edu.br.

Link para o Lattes: http://lattes.cnpq.br/4936548402674961;

${ }^{3}$ Instituto Federal Sul-rio-grandense -Campus Lajeado. Email: claudiacarvalho@ifsul.edu.br.

Link para o Lattes: http://lattes.cnpq.br/2445305613209271;

${ }^{4}$ Instituto Federal Sul-rio-grandense -Campus Lajeado. Email: ismaellima@ifsul.edu.br.

Link para o Lattes: http://lattes.cnpq.br/0010793929340285;

5 Instituto Federal Sul-rio-grandense -Campus Lajeado. Email: williamsperb@ifsul.edu.br.

Link para o Lattes: http://lattes.cnpq.br/1357022103985093;

6 Instituto Federal Sul-rio-grandense -Campus Lajeado. Email: wemersonoliveira@ifsul.edu.br.

Link para o Lattes: http://lattes.cnpq.br/4906043209502220. 
Abstract: At school, we have the possibility to involve environmental education in an interdisciplinary way, seeking to raise awareness in a critical and transforming way in the community, interfering in habits beyond its walls. This work presents the actions developed, throughout two years, in a technical school with high school students, from the core of integrated environmental management. The actions consist in lectures, awareness campaigns, waste sorting, vegetable garden, soap making and action in the community, also introducing aspects of the scientific methodology. Only through awareness will we be able to develop an environmental and sustainable culture, in which quality of life can prevail, guaranteeing the future for the current and next generations.

Keywords: School; Awareness; Action; Environment.

\section{Apresentação da proposta}

O Campus Lajeado do Instituto Federal Sul-rio-grandense (IFSul Campus Lajeado), em consonância com o Plano de Desenvolvimento Institucional, possui compromisso com o processo educativo e com 0 desenvolvimento do indivíduo em todas as suas dimensões, por meio de uma educação humano-científico-tecnológica (IFSUL, 2014). Para tanto, e como produtor de conhecimentos científicos e tecnológicos, assim como disseminador de práticas culturais, o Núcleo de Gestão Ambiental Integrada (NUGAI) vem sendo desafiado a estabelecer relações de parcerias que ampliem e qualifiquem o fluxo de conhecimento e práticas de interesse regional. Corrobora com esta ideia a ação desenvolvida a partir do projeto de Educação Ambiental: APLICAÇÃO DO PRINCÍPIO DOS 3R'S NO RESÍDUO SÓLIDO A PARTIR DE UM NÚCLEO AMBIENTAL.

A Educação Ambiental é parte do movimento ecológico, surgindo da preocupação da sociedade com a manutenção da vida e com a qualidade da existência das gerações atual e futura. Assim, como suporte para as questões ambientais e de sustentabilidade no IFSul - Campus Lajeado, o NUGAI foi criado, sendo recomendada sua implementação em todos os Campi do Instituto Federal Sul-rio-grandense.

Atualmente, é papel da escola informar e orientar seu estudante sobre a atual relação do ser humano com a natureza e sobre como ele pode atuar para modificar essa relação e transformar (mesmo que com poucas ações) o meio em que está inserido em algo melhor. A ideia de conhecimento requer que o sujeito participe do mundo ao seu redor, propõe modificação perante a realidade e exige a reflexão crítica (FREIRE, 1983). Dessa forma, o trabalho realizado objetivou a compreensão, por parte de cada estudante, em relação a sua inserção no meio ambiente e como ele é parte importante das mudanças que nele ocorrem. Procurou-se agir para propiciar uma alteração de atitudes e desenvolver a participação ativa para com a questão ambiental, contribuindo para mudanças e construção de um mundo melhor. 


\section{Referencial teórico}

Nos Institutos Federais, conforme Lei de criação n. 011.892 de 2008, a Educação Ambiental está vinculada às finalidades e características institucionais, pois o Art. 6aduz: "promover a produção, o desenvolvimento e a transferência de tecnologias sociais, notadamente as voltadas à preservação do meio ambiente" (BRASIL, 2008).

De um modo geral, o NUGAl é um órgão de assessoramento à Direção, concebido para desenvolver estudos e práticas inovadoras de gestão ambiental, a fim de atender às crescentes demandas e contribuir estrategicamente, junto das políticas públicas, para a sustentabilidade da instituição (IFSUL, 2015). Dentro dessa perspectiva, as ações de Educação Ambiental no NUGAl foram concebidas e executadas. Compõe o núcleo: servidores docentes e técnicos administrativos, bem como estudantes do IFSul - Campus Lajeado, de todas as modalidades, na condição de voluntários.

Compete ao NUGAI, em cada Campus do Instituto Federal Sul-riograndense: o desenvolvimento de ações para a consolidação de um centro de referência para questões ambientais, que estimule processos de gestão ambiental inovadores e integrados; implemente, estimule e aperfeiçoe boas práticas ambientais, com o intuito de melhorar continuamente os métodos, as ferramentas e as técnicas aplicadas à gestão ambiental; que coordene atividades específicas, relacionadas à gestão ambiental, como coleta e destinação de todos os tipos de resíduos, manejo e manutenção da vegetação e áreas externas, entre outras; que faça cumprir os objetivos da Política Nacional de Resíduos Sólidos, em especial, os relativos ao consumo consciente, a não geração e a minimização de resíduos; que prime pela prioridade nas aquisições e contratações governamentais por produtos reciclados e recicláveis, bem como pela aquisição de bens, serviços e obras que considerem critérios compatíveis com padrões de consumo social e ambientalmente sustentáveis (IFSUL, 2015).

Além das competências do NUGAI, as atividades também se pautaram em alguns ideais e documentos balizadores, elencados, resumidamente, a seguir.

\section{Objetivos de Desenvolvimento Sustentável}

A vida no planeta Terra, da forma como estamos vivendo, está ficando cada dia mais insustentável. Os atuais padrões de consumo dos recursos naturais disponíveis, juntamente com o alto crescimento populacional, vêm acarretando sérios danos ao meio ambiente. Em decorrência disso, a Organização das Nações Unidas (ONU) elaborou, em 2015, uma agenda de objetivos para o desenvolvimento sustentável até 2030. Esses objetivos equilibram as três dimensões do desenvolvimento sustentável: a econômica, a social e a ambiental. $O$ primeiro objetivo é trabalhar conjuntamente para a erradicação da pobreza em todas as suas formas e dimensões, incluindo a 
pobreza extrema, sendo o maior desafio global e um requisito indispensável para o desenvolvimento sustentável. Neste projeto enfatizou-se, também, direta ou indiretamente, os seguintes objetivos: $3^{\circ}$ - Saúde e bem-estar; $4^{\circ}$ Educação de Qualidade; $6^{\circ}$ - Água potável e Saneamento; $12^{\circ}$ - Consumo e Produção Responsáveis; $13^{\circ}$ - Ação contra a mudança global do clima; $14^{\circ}$ Vida na água e $15^{\circ}$ - Vida terrestre (ONU, 2015).

\section{Política Nacional de Educação Ambiental}

Conscientizar a população para os cuidados com o meio ambiente é uma tarefa de grande importância para que sejam alcançados os resultados necessários em prol do desenvolvimento sustentável do planeta. Tal fato é estimulado pela Política Nacional de Educação Ambiental - PNEA, regulamentado pela Lei no 9.795, de 1999, via Decreto no 4.281, de 25 de junho de 2002, em que fica explícita a inclusão da Educação Ambiental - EA nos currículos escolares: "A Educação Ambiental será desenvolvida como uma prática educativa integrada, contínua e permanente em todos os níveis e modalidades de ensino formal' (BRASIL, 2002, p.2).

Ao realizar as diferentes ações num ambiente escolar, embora fora do espaço das aulas propriamente ditas, propôs-se um novo olhar na relação entre o ser humano e o ambiente, além de examinar as principais questões ambientais do ponto de vista local, regional, nacional e internacional, conforme recomendado por Dias (2004); e de defender uma ação conjunta, uns com os outros, pois todos são responsáveis e estão em posição de atuação na questão ambiental (CARVALHO, 2004).

\section{Política Nacional do Resíduo Sólido}

Também, é essencial conhecer acerca dos resíduos sólidos, pois estão inteiramente relacionados aos hábitos de consumo. Os resíduos sólidos (RS) configuram como um dos maiores problemas ambientais, posto que o inadequado tratamento traz a deterioração da qualidade das águas e dos solos. No Brasil, de acordo com a Política Nacional de Resíduos Sólidos - PNRS (Lei n.- 12.305/10), os resíduos orgânicos correspondem a $51,4 \%$ dos resíduos sólidos urbanos gerados no país (BRASIL, 2010). O resíduo sólido, de acordo com a Norma Brasileira (ABNT - NBR) n.․ 10.004/2004, é definido como "resíduos nos estados sólido e semissólido, que resultam de atividades da comunidade de origem: industrial, doméstica, hospitalar, comercial, agrícola, de serviços e de varrição" (NBR 10.004, 2004, p. 13). Se gerenciados de forma adequada, os RS podem adquirir valor comercial e ser introduzidos no mercado como matéria-prima para a geração de novos produtos.

O princípio dos 5R's contribui significativamente para auxiliar na busca pelo consumo sustentável dos recursos naturais e para adequar as práticas de reutilização do que é considerado inútil e indesejável. Esta política dos 5R's adveio da necessidade de conciliar as atividades humanas com a proteção e 
preservação da natureza. A letra $R$ apresenta os seguintes significados: Repensar: pois repensar suas práticas é o início da mudança; Recusar: para que sejamos críticos em relação ao consumismo; Reduzir: significa saber economizar os recursos naturais; Reutilizar: está relacionado ao utilizar novamente; Reciclar: trata-se do reaproveitamento de um produto de modo que ele se torne matéria-prima para a fabricação de outro objeto. (MACHADO, 2018; ECO-UNIFESP, 2019; SANTOS, 2019).

\section{BNCC - Educação Ambiental e interdisciplinaridade}

A Base Nacional Comum Curricular (BNCC), que orienta o processo formativo atual, determina que a "educação deve afirmar valores e estimular ações que contribuam para a transformação da sociedade, tornando-a mais humana, socialmente justa e, também, voltada para a preservação da natureza" (BRASIL, 2018, p. 8), mostrando-se alinhada à Agenda 2030 da ONU. Ainda, a BNCC evidencia que os estudantes devam se envolver com uma série de fatores do seu cotidiano, sendo essas vivências o ponto de partida para a construção das noções sobre tudo o que os cercam, os materiais, os recursos, os fenômenos.

Ao se pensar sobre a transposição da temática ambiental, tem-se a oportunidade de procurar novas saídas, resoluções, conceitos e, principalmente, práticas e atitudes, num processo educativo em que o alicerce principal é a sustentabilidade, a participação, o diálogo e a interdependência em todas as áreas do conhecimento. Conforme Pombo (2006) "a interdisciplinaridade existe, sobretudo, como prática, afirmando que ela se traduz na realização de diferentes tipos de experiências interdisciplinares de investigação" (p.225). Cientes desse processo, pretendeu-se, também, focar a Educação Ambiental com o viés crítico e emancipatório, ou seja, da Educação Ambiental transformadora que:

baseia-se no princípio de que as certezas são relativas; na crítica e autocrítica constante e na ação política como forma de se estabelecer movimentos emancipatórios e de transformação social que possibilitem o estabelecimento de novos patamares de relações na natureza (LOUREIRO, 2004, apud ZITZKE; CALIXTO, 2019, p. 311).

Embasados por essas premissas e percebendo o meio ambiente como um laboratório de infinitas possibilidades, o trabalho APLICAÇÃO DO PRINCÍPIO DOS 3R'S NO RESÍDUO SÓLIDO foi proposto e será relatado neste artigo, numa ordem quase cronológica, pois, em alguns casos, as ações foram se sobrepondo ao adquirir importância junto à comunidade do IFSul Campus Lajeado. 


\section{Desenvolvendo as ações}

As ações foram arquitetadas pelo NUGAI e realizadas no IFSul Campus Lajeado, localizado na região do Vale do Taquari, no estado do Rio Grande do Sul. Seu desenvolvimento iniciou no ano de 2018 e teve seu encerramento no ano posterior. Contou com a participação dos servidores (administrativos e docentes), terceirizados e estudantes, totalizando, aproximadamente, 450 participantes.

A partir de levantamentos e reconhecimentos de situações pontuais, realizados pelos membros do NUGAI, sobre o descarte incorreto e geração excessiva de RS no IFSul - Campus Lajeado, foram projetadas, coletivamente, ações que pudessem ser desenvolvidas para a melhoria dessa realidade. Diante disso, sentiu-se a necessidade de se aprofundar e aplicar a política dos 5R's para conciliar as atividades humanas com a proteção e preservação da natureza, bem como do ambiente escolar. No entanto, diante da realidade investigada, observou-se que, inicialmente, seria necessária a aplicação dos princípios Reciclar, Repensar e Reduzir, denominada pedagogicamente como "3R'sul", no gerenciamento do RS no Campus.

A redução, reutilização e reciclagem de materiais tem como objetivo a diminuição do impacto sobre o meio ambiente, através de duas perspectivas. Por um lado, a diminuição da quantidade de matéria-prima empregada na produção de novos produtos. $\mathrm{E}$, por outro, a redução da quantidade de desperdícios resultantes do alto padrão de consumo humano, depositados no meio ambiente sem que este tenha capacidade de os absorver.

\section{O Início de tudo: Análise gravimétrica}

O projeto "Aplicação do princípio dos "3R'sul" no RS do IFSul - Campus Lajeado" foi realizado a partir dos estudos da caracterização gravimétrica realizada no ano de 2018 pelo NUGAI. Essa primeira análise teve o objetivo de conhecer o perfil de RS que eram gerados no Campus.

Toda a análise gravimétrica, realizada nestas e em outras ações, foi baseada no processo descrito por Konrad e colaboradores (2010). Iniciou-se, em 2018, com a análise da separação dos resíduos coletados durante seis semanas (julho e agosto) consecutivas. O RS foi previamente depositado em uma sala exclusiva para a análise e, após, pesado, utilizando-se de uma balança tipo pêndulo - a pesagem foi realizada sempre às sextas-feiras. Posteriormente, os resíduos pesados e separados, em recicláveis e orgânicos, foram encaminhados ao depósito de lixo para recolhimento futuro pelo serviço de coleta urbano municipal. A Tabela 1 mostra os resultados da análise: 
Tabela 1: Caracterização gravimétrica dos resíduos sólidos do IFSul - Campus Lajeado, por semana, no ano de 2018.

\begin{tabular}{|c|c|c|c|c|c|c|c|}
\hline \multicolumn{8}{|c|}{ Pesagem por semana em quilogramas $(\mathrm{kg})$} \\
\hline Material & $\begin{array}{c}1^{\circ} \\
\text { Pesagem }\end{array}$ & $\begin{array}{c}2^{\circ} \\
\text { Pesagem }\end{array}$ & $\begin{array}{c}3^{\circ} \\
\text { Pesagem }\end{array}$ & $\begin{array}{c}4^{\circ} \\
\text { Pesagem } \\
\end{array}$ & $\begin{array}{c}50 \\
\text { Pesagem } \\
\end{array}$ & $\begin{array}{c}6^{\circ} \\
\text { Pesagem } \\
\end{array}$ & Total \\
\hline Orgânico & 23,76 & 17,99 & 13,35 & 22,95 & 31,16 & 8,86 & 118,07 \\
\hline Papel Sanitário & 14,79 & 9,5 & 8,16 & 14,05 & 15,44 & 6,98 & 68,92 \\
\hline Plástico & 6,32 & 6,05 & 4,69 & 5,07 & 5,3 & 5,66 & 33,09 \\
\hline Metal & 0,68 & 0,9 & 0,65 & 0,49 & 2,05 & - & 4,77 \\
\hline Papel & 11,3 & 2,65 & 2,21 & 3,99 & 3,01 & 1,69 & 24,85 \\
\hline Vidro & - & - & - & - & - & - & - \\
\hline Outros & - & - & - & 0,42 & - & - & - \\
\hline Total de RS & 56,85 & 37,09 & 29,06 & 46,97 & 56,96 & 23,19 & 249,7 \\
\hline
\end{tabular}

Durante as seis semanas, pesou-se aproximadamente $250 \mathrm{~kg}$ de RS. Vale destacar que foi um valor alto, considerando que, em 2018, o Instituto iniciava as atividades com o ensino médio integrado, apresentando somente duas turmas, totalizando 64 estudantes, divididos em dois turnos. Das seis semanas analisadas, destacou-se a primeira e a quinta semana, que apresentaram a maior pesagem comparada com as demais, valores próximos de $56,9 \mathrm{~kg}$. A diferença entre as duas semanas foram os orgânicos, que foi maior na quinta semana e o papel, que foi maior na primeira semana. A sexta semana foi a que apresentou a menor pesagem total, não sendo encontrados resíduos metálicos, diferentemente das demais pesagens.

Com o aumento considerável no número de alunos no ano de 2019 (três vezes mais), pela abertura de mais uma área técnica integrada, pensou-se, então, na realização de uma campanha de conscientização ambiental (descrita no item abaixo) como forma preventiva. O objetivo foi focar na correta separação dos resíduos em: orgânico para composteira, orgânico rejeito e reciclável. A fim de se verificar o efeito da campanha, foi promovida nova pesagem do RS do Campus Lajeado em dois momentos: antes e após a campanha de conscientização ambiental. A análise gravimétrica seguiu os mesmos padrões descritos anteriormente e os princípios de reduzir e repensar (“ $3 R$ 'sul") foram os mais focados. O período de coleta foi de cinco dias em cada situação.

$\mathrm{Na}$ comparação, foi possível constatar que o perfil do RS não apresentou grande variação entre os dois momentos, praticamente o tipo de RS produzido foi sempre o mesmo. Observou-se um aumento na porcentagem do papel pré e pós-palestra, comparado com 2018, que se deu pelo descarte de papelão decorrente da aquisição de materiais no IFSul - Campus Lajeado. No entanto, vale ressaltar que o percentual de plástico reduziu em aproximadamente $3 \%$, comparado com o ano de 2018. Percebeu-se que na redução do resíduo plástico, o copo descartável foi destaque, mostrando a eficiência da campanha "Adote a sua caneca" (descrita no item abaixo) que fez a diferença no material descartado. 
Tabela 2: Comparação entre os resíduos sólidos caracterizado em Lajeado e o produzido no IFSul - Campus Lajeado no ano de 2019.

\begin{tabular}{|c|c|c|c|c|c|c|c|c|}
\hline \multirow[t]{2}{*}{ Material } & \multirow[t]{2}{*}{ Lajeado* } & \multicolumn{2}{|c|}{ Análise 2018} & \multicolumn{2}{|c|}{$\begin{array}{c}\text { Análise pré- } \\
\text { palestra }\end{array}$} & \multicolumn{2}{|c|}{$\begin{array}{c}\text { Análise pós- } \\
\text { palestra }\end{array}$} & \multirow[t]{2}{*}{ Total $(\mathbf{k g})$} \\
\hline & & $\mathrm{Kg}^{\star \star}$ & $\%$ & kg & $\%$ & kg & $\%$ & \\
\hline Material orgânico & $46,10 \%$ & --- & $---\%$ & --- & $----\%$ & 20,05 & $10,80 \%$ & 20,05 \\
\hline Papel Sanitário & $8,30 \%$ & 11,48 & $27,55 \%$ & 15,64 & $36,20 \%$ & 25,06 & $38,50 \%$ & 109,62 \\
\hline Plástico & $12,60 \%$ & 5,51 & $13,22 \%$ & 2,26 & $5,20 \%$ & 6,78 & $10,40 \%$ & 42,13 \\
\hline Metal & $1,60 \%$ & 0,80 & $1,90 \%$ & 0,70 & $1,60 \%$ & 0,95 & $1,50 \%$ & 6,42 \\
\hline Papel & $5,60 \%$ & 4,14 & $9,93 \%$ & 8,41 & $19,40 \%$ & 5,31 & $8,10 \%$ & 38,57 \\
\hline Vidro & $2,60 \%$ & 0,00 & $0,00 \%$ & 0,00 & $0,00 \%$ & 0,00 & $0,00 \%$ & 0,00 \\
\hline Rejeito & --- & & $47,20 \%$ & & $37,60 \%$ & & $30,80 \%$ & 0,00 \\
\hline Total de resíduo & b́lido (kg) & $\begin{array}{c}131,6 \\
3\end{array}$ & & 27,01 & & 58,15 & & 216,79 \\
\hline
\end{tabular}

Fonte: Elaborada pelos autores. *Dados retirados da pesquisa de Konrad e colaboradores (2010). ${ }^{*}$ Cálculo equivalente ao número de dias das análises pré e pós-palestra (valor total dividido pelas 6 semanas).

Outro ponto que merece destaque é que, em 2018, não havia a separação adequada do resíduo orgânico, pois restos de comida eram depositados conjuntamente com restos de erva, borra de café e cascas de frutas não cítricas. A separação destes resíduos, em especial, foi enfatizada na campanha de conscientização, pois trata-se do material que pode ser utilizado na composteira.

\section{Compartilhando conhecimento: Sensibilização Ambiental e Campanha de Conscientização}

Após os resultados obtidos da análise gravimétrica realizada em 2018, foram propostas ações para a sensibilização e conscientização de toda comunidade escolar (estudantes, docentes, técnicos administrativos e terceirizados). Fizeram parte desta ação:

\section{Palestra: "3R'sul” - reciclar, reduzir e repensar}

Para que os estudantes integrantes do NUGAl tivessem efetiva participação da campanha, foi proposto que um deles pensasse, planejasse e apresentasse a palestra. $O$ intuito foi conscientizar toda a comunidade escolar ( $n=450$ pessoas) sobre a correta separação do RS no sistema de lixeiras que o NUGAI já tinha implantado, baseado nos " $3 R$ 'sul". Uma parte do material utilizado na palestra está apresentado na figura 1.

Observou-se que, após o momento de oratória do estudante, ocorreu uma mudança no comportamento da comunidade escolar de uma forma geral. Percebeu-se uma maior preocupação no descarte correto dos RS. Outro resultado positivo foi a presença dos recipientes metálicos de marmitas descartados limpos na lixeira de "Metal". Anteriormente, este material era simplesmente descartado junto ao material orgânico/rejeito. 


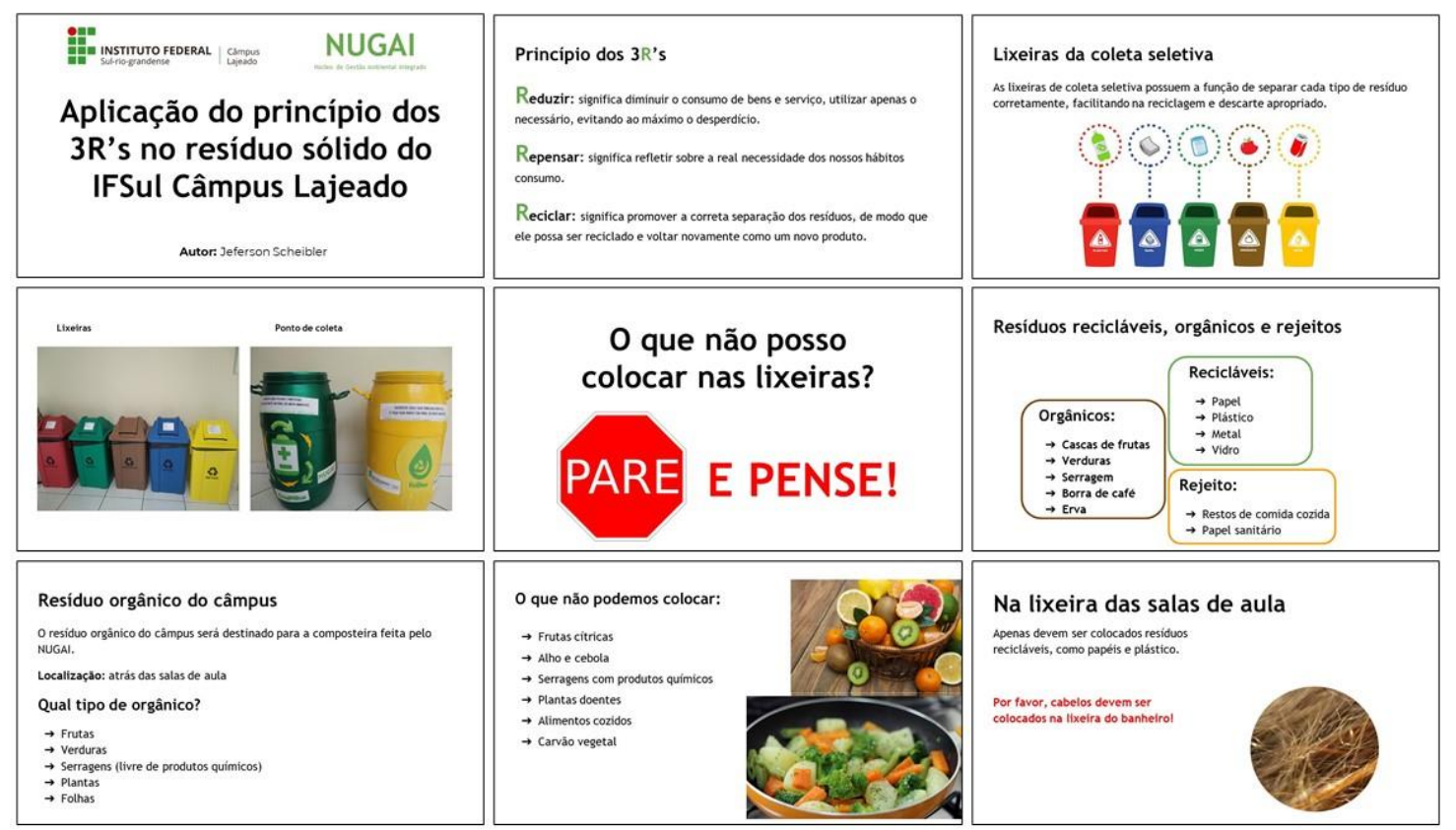

Figura 1: Parte do material utilizado na palestra de sensibilização e conscientização de Educação Ambiental. Fonte: Elaborada pelos autores.

Cabe ressaltar que na análise gravimétrica do resíduo pré-palestra foi percebida a presença de cabelo nas mais diferentes lixeiras do IFSul - Campus Lajeado. Na palestra, foi recomendado que o descarte de tal resíduo fosse realizado apenas nas lixeiras localizadas nos banheiros. Positivamente, percebemos que na análise pós-palestra não foram encontrados cabelos nas lixeiras de resíduo reciclado ou orgânico.

\section{Dia Mundial da Água}

Outra ação de Educação Ambiental foi relacionada com a preservação dos rios, lagos e mares no Dia Mundial da Água, que acontece em 22 de março. A temática levou em consideração a poluição das águas causada pelos rejeitos das barragens, Mariana e Brumadinho, que se romperam no estado de Minas Gerais. Para tanto, foi feita a montagem de um espaço simulando um rio sofrendo um processo de poluição com diversos materiais, sendo destacado em cada tipo de material seu tempo de degradação. Além disso, foi feita uma variação de cores, entre o branco (água limpa), azul claro (água com sua biodiversidade), azul escuro (água poluída com materiais diverso) e marrom (água poluída com o rejeito de mineração), indicando o processo de poluição e acúmulo dos rejeitos das mineradoras (Figura 2). 


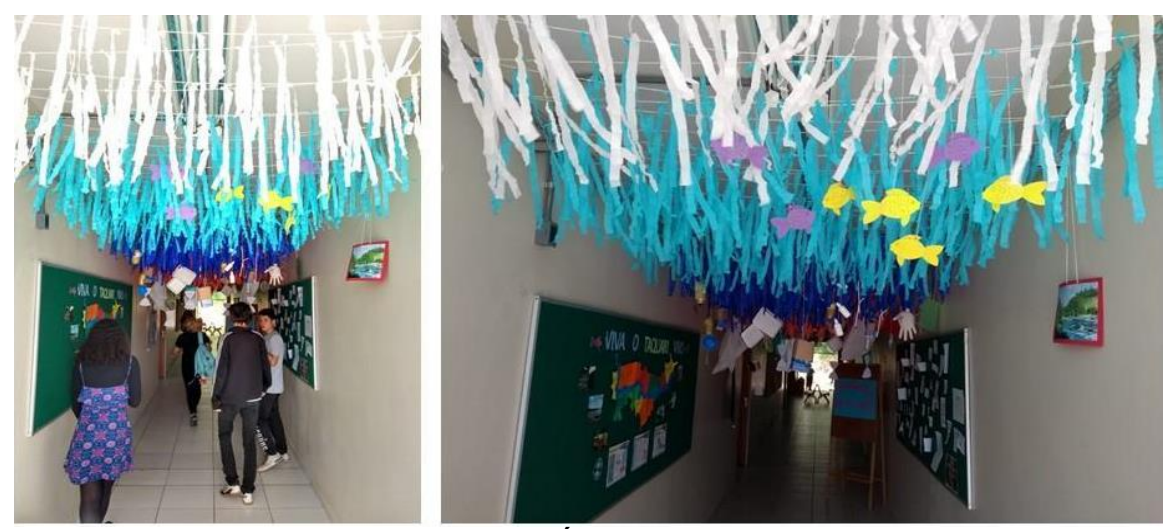

Figura 2: Ação do Dia Mundial da Água. Fonte: Elaborada pelos autores.

Aproveitando o momento, também foram feitas: a divulgação do evento "Viva o Taquari Vivo" (descrito abaixo) e a construção de um painel ilustrativo com informações sobre o Rio Taquari (Figura 2).

\section{Dia Mundial do Meio Ambiente}

Inicialmente, foi divulgado para os estudantes, em três dias consecutivos, o desafio proposto pela ONU em seu site (Figura 3A), ONU Meio Ambiente, para que postassem uma foto sua nas redes sociais usando uma máscara ou pano sobre a boca e nariz, com o objetivo de sensibilizar as autoridades para a promoção da redução de $\mathrm{CO}_{2}$. Estas ações foram promovidas durante três dias.
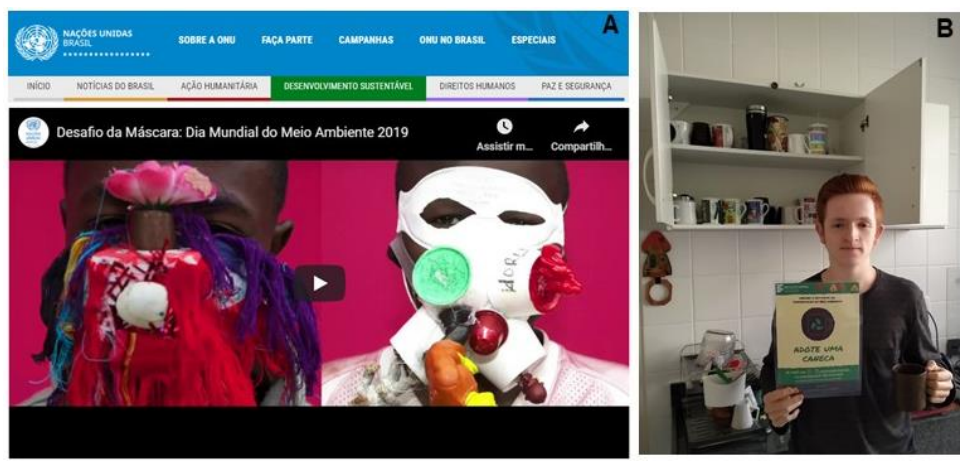

Figura 3: Ações do Dia Mundial do Meio Ambiente. (A) Desafio proposto pela ONU; (B) Cartazes da campanha "Adote uma caneca". Fonte: Elaborada pelos autores (ONU, 2019).

Paralelamente à atividade anterior, foi lançada a campanha "Adote uma Caneca" com a distribuição de cartazes enfatizando a necessidade da redução do número de copos plásticos, por meio do uso de caneca nas dependências do IFSul - Campus Lajeado (Figura 3B). 


\section{Visita ao Aterro Sanitário}

Os membros do NUGAI também realizaram uma visita ao aterro sanitário municipal de Lajeado/RS, localizado no bairro Conventos. A ideia foi conhecer a estrutura e condições para a realização de futuras ações com os estudantes, como visitas técnicas. O aterro conta com uma estrutura para recebimento do RS, separação do RS reciclável, através da parceria com uma cooperativa de catadores, e tratamento do chorume liberado do aterro (Figura 4). A visita foi guiada pela bióloga que atua na secretária de Meio Ambiente da Prefeitura Municipal de Lajeado/RS.

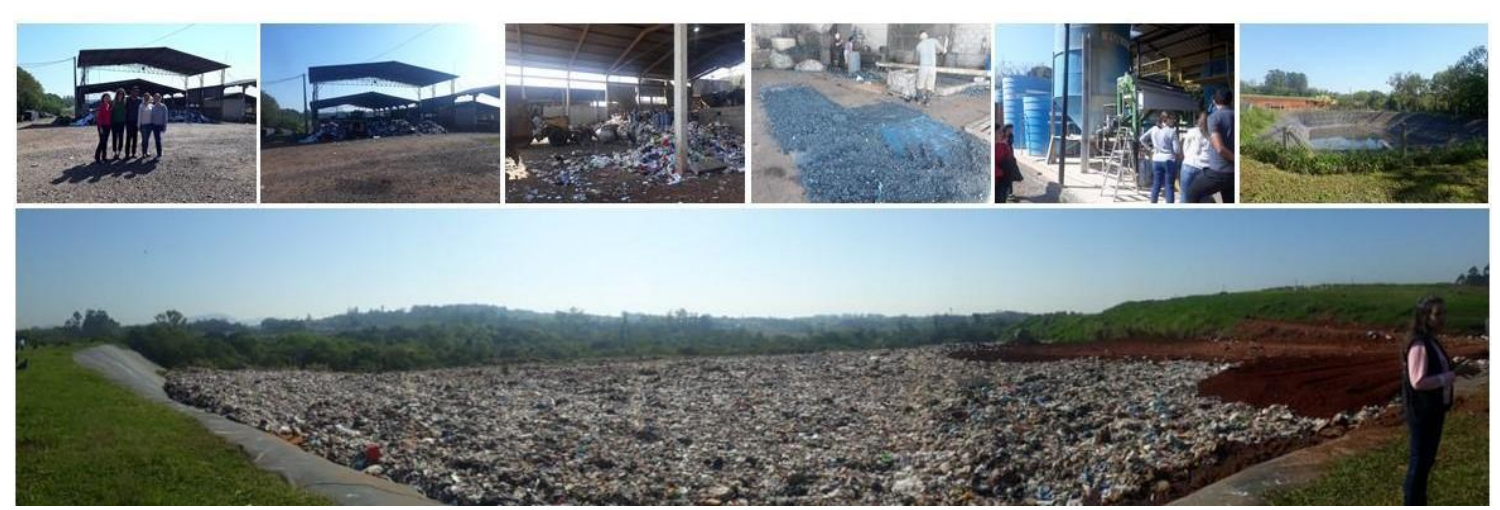

Figura 4: Visita ao aterro sanitário municipal de Lajeado. Fonte: Elaborada pelos autores.

\section{Cidadão ativo: Viva o Taquari Vivo}

A Educação Ambiental não deve ser restrita somente ao ambiente escolar, sendo necessária a sua ampliação para o público externo como forma de conscientização. Diante disso, integrantes do NUGAI e estudantes do ensino médio integrado participaram de eventos ambientais desenvolvidos na cidade com o intuito de fortalecer e oportunizar novas experiências ambientais.

"Viva o Taquari Vivo" (Figura 5) foi a primeira ação ambiental externa que o NUGAI participou como instituição. É um projeto anual promovido pela Associação Comercial e Industrial de Lajeado, (ACIL) e pela Organização Não Governamental (ONG) Parceiros Voluntários e possui como lema: sensibilizar a comunidade regional acerca das questões ambientais relacionadas à conservação de recursos hídricos através da promoção de valores ambientais para o despertar de novas atitudes individuais e coletivas.

O projeto Viva o Taquari Vivo objetiva recolher RS das margens e do leito do rio Taquari e, na $13^{\underline{a}}$ edição, na qual participamos, foram retiradas 3,6 toneladas de RS com a ajuda de mais de 700 voluntários. Após a coleta, o material recolhido foi encaminhado aos aterros sanitários dos municípios envolvidos. Segundo estimativa da ACIL, no total das 13 edições já foram retiradas 43 toneladas de RS do rio, com a participação de 6.550 voluntários. 
Os representantes do IFSul - Campus Lajeado tiveram participação ativa durante o desenvolvimento de toda a ação e o aprendizado fica evidente no relato de uma das estudantes envolvidas na atividade:

"Foi a primeira edição em que eu participei e confesso que participar fez com que eu tomasse um "choque de realidade", porque tirei apenas algumas horas do meu dia pra fazer o mínimo, que é preservar e cuidar do que é meu e de todos em minha volta. É uma pena que as pessoas ainda veem como um ato "extraordinário" participar de movimentos do gênero, quando na verdade deveria ser uma atitude espontânea incorporada no nosso dia a dia. O que ainda precisa acontecer e de que forma a natureza tem que mostrar que já não há mais o que ser explorado?"

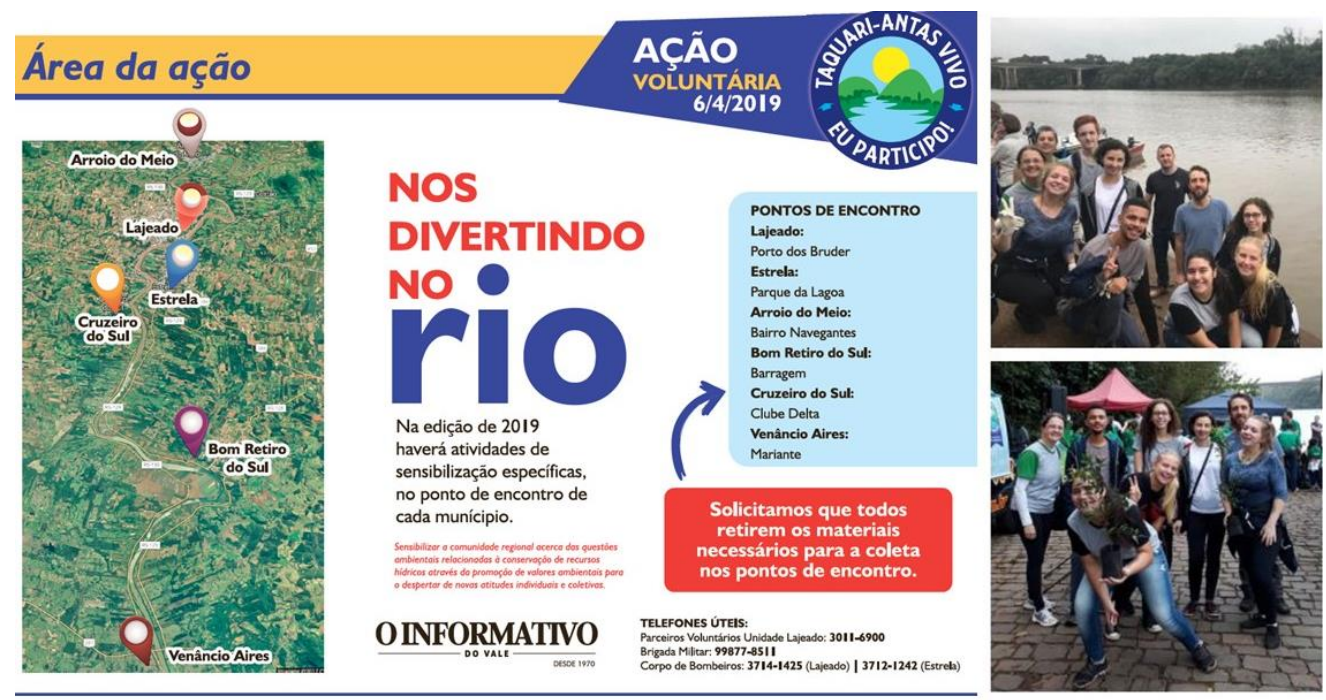

Figura 5: Cartaz ilustrativo da campanha "Viva o Taquari Vivo" e os voluntários representantes do IFSul - Campus Lajeado. Fonte: Elaborado pelos autores.

\section{O olhar ambiental: Conhecendo a percepção do outro}

O município de Lajeado/RS possui preocupação com as questões ambientais. Nota-se que ocorrem, com certa frequência, eventos e movimentos vinculados ao meio ambiente durante o ano. O município possui coleta seletiva e o seu próprio aterro sanitário, com tratamento do chorume produzido antes de ser lançado novamente no ambiente. Diante dessa preocupação, várias escolas municipais possuem projetos com objetivo de educação para o ambiente. Visando, então, conhecer o trabalho realizado em uma escola referência em ações ambientais do município e trocar conhecimentos sobre a construção e a utilização de uma composteira para a instalação de uma própria no IFSul - Campus Lajeado, foi realizada uma entrevista, com 15 perguntas, com o professor idealizador do projeto na escola. 
Além disso, buscando conhecer a percepção dos estudantes do IFSul Campus Lajeado, em relação ao conceito de sustentabilidade, no ano de 2019, foi realizado um levantamento, através de uma pesquisa de campo, por meio de um questionário voluntário on-line. A partir dos resultados, foi possível identificar e traçar estratégias de Educação Ambiental, voltadas especialmente para a necessidade e realidade dos estudantes, permitindo direcionar as ações que seriam desenvolvidas no Campus.

\section{Descarte consciente: Identificação e implementação de pontos de coleta}

Procurando melhorar a coleta seletiva realizada no IFSul - Campus Lajeado, as lixeiras receberam nova identificação. Além disso, dentre os pontos levantados nas etapas anteriores, um bastante crítico foi o descarte de pilhas, baterias e óleo de cozinha. Assim, buscando solucionar esse problema, houve a implantação de pontos de coleta de pilhas, baterias e óleo de cozinha usado, no saguão do prédio administrativo, demonstrado na Figura 6. A partir do resíduo de óleo de cozinha usado que foi coletado, a equipe do NUGAl, juntamente com os estudantes membros, confeccionaram sabão que foi distribuído para os servidores do IFSul - Campus Lajeado, como descrito no próximo item.

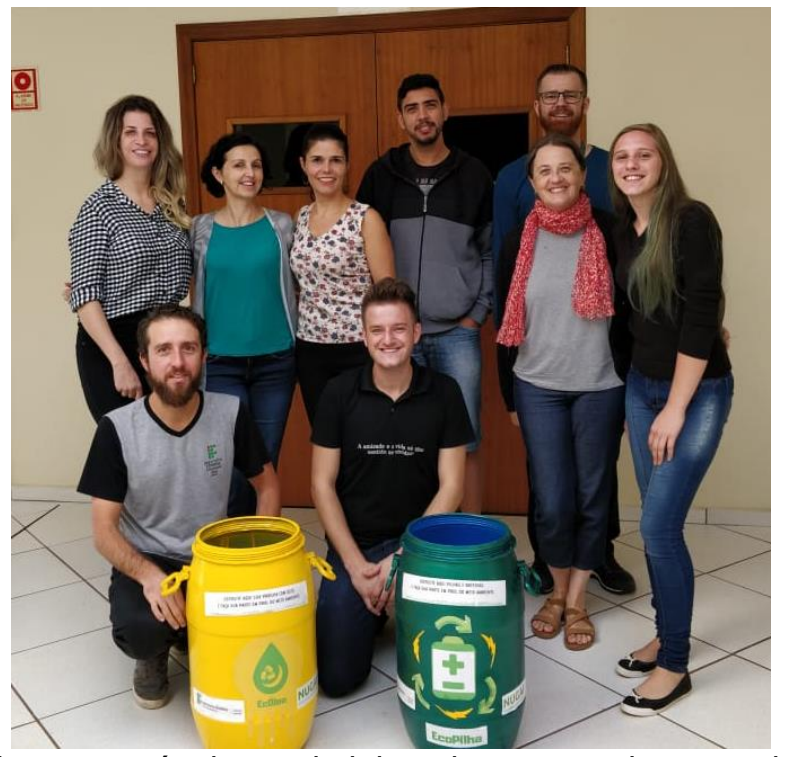

Figura 6: Membros - docentes, técnicos administrativos e estudantes - do NUGAI, implantando os pontos de coleta de baterias, pilhas e óleo usado. Fonte: Elaborado pelos autores.

Em um momento pontual durante o ano de 2019, no mês de novembro, foi arquitetada coleta de equipamentos eletroeletrônicos. Essa ação foi realizada em parceria com a Secretaria Municipal do Meio Ambiente. Foi disponibilizado um local, previamente identificado, no prédio administrativo e durante o período de um mês a comunidade escolar pôde realizar o descarte do seu lixo eletrônico. 


\section{Do artesanato ao conhecimento: Utilização consciente do resíduo de óleo na produção de sabão}

Para o aproveitamento dos $6,6 \mathrm{~kg}$ de óleo de cozinha usado, recolhidos em 5 meses, estudou-se a produção de sabão, utilizando soda cáustica $(\mathrm{NaOH})$ e água como reagentes principais. Foram avaliados, também, os reagentes secundários: álcool, vinagre, glicerina e aromatizantes; além da variação do modo de preparo. Essa ação também se caracterizou como pesquisa, uma vez que foram testados três protocolos de produção de sabão encontrados nas plataformas on-line. A verificação da qualidade, para posterior divulgação da receita do sabão em oficinas de reciclagem do óleo de cozinha, foi feita através de análise de $\mathrm{pH}$, praticidade e tempo necessário de produção.

Tabela 3: Processos e análises da produção do sabão com óleo de cozinha usado.

\begin{tabular}{cccc}
\hline & PROCESSOS TESTADOS - Produção de sabão & \\
\hline Condições $^{*}$ & Protocolo 1 & Protocolo 2 & Protocolo 3 \\
\hline NaOH $(\mathrm{g})$ & 135 & 125 & 125 \\
Água $(\mathrm{mL})$ & 140 & 140 & 140 \\
Álcool $(\mathrm{mL})$ & 25 & 100 & 100 \\
Vinagre $(\mathrm{mL})$ & - & 40 & 40 \\
Glicerina $(\mathrm{g})$ & - & 100 & 100 \\
Aromatizante $(\mathrm{mL})$ & 60 & 60 & 60 \\
Temperatura $\left({ }^{\circ} \mathrm{C}\right)$ & 25 & 60 & 25 \\
\hline \multicolumn{5}{c}{} & \multicolumn{4}{c}{ RESULTADOS } & $10-11$ \\
\hline pH ${ }^{\star *}$ & 10 & $10-11$ & ++ \\
Praticidade & +++ & + & $20-30$ \\
Tempo $(\mathrm{h})$ & $20-30$ & $30-40$ & pouca solidificação \\
Aparência & homogênea e lisa & formou grumos laminares
\end{tabular}

Fonte: Elaborada pelos autores.

\section{Reaproveitamento: Do lixo à produção de alimentos}

A partir do conceito de uma Educação para o Meio Ambiente, que se constitui do processo pelo qual se busca o engajamento ativo do estudante, que aprende a resolver e prevenir os problemas ambientais, o NUGAI promoveu a ação da construção de uma horta comunitária. Nesse sentido, a ideia da horta foi tema de uma tarefa na gincana do IFSul - Campus Lajeado (2019), evento já consolidado no calendário acadêmico do Campus. Cada equipe teve o desafio de propor um layout de uma horta com materiais recicláveis. Após o julgamento das propostas, uma delas foi escolhida e o projeto foi utilizado para a construção da horta, como ilustrado na Figura 7.

Para que se pudesse realizar o plantio, inicialmente, foi necessária uma análise e posterior correção do solo. Para isso, foi realizada parceria com a Associação Riograndense de Empreendimentos de Assistência Técnica e Extensão Rural (EMATER), instituição que presta assessoria gratuita às escolas com implementação de hortas na região. Foi realizada a coleta do solo por um técnico agrônomo, sendo enviada ao laboratório de Solos da Universidade Federal do Rio Grande do Sul (UFRGS). A EMATER realizou 
diversos encontros e reuniões com os membros do NUGAI, para orientação das medidas necessárias para viabilização da horta. As plantas escolhidas para compor a horta foram: Pimpinella anisum (Erva doce), Cymbopogon winterianus (Citronela), Plectranthus barbatus (Boldo-brasileiro), Cymbopogon citratus (Capim-cidreira), Mentha spicata (Hortelã), Petroselinum crispum (Salsa), Matricaria recutita (Camomila), Rosmarinus officinalis (Alecrim), Achyrocline satureioides (Marcela) e Ocimum basilicum (Manjericão).

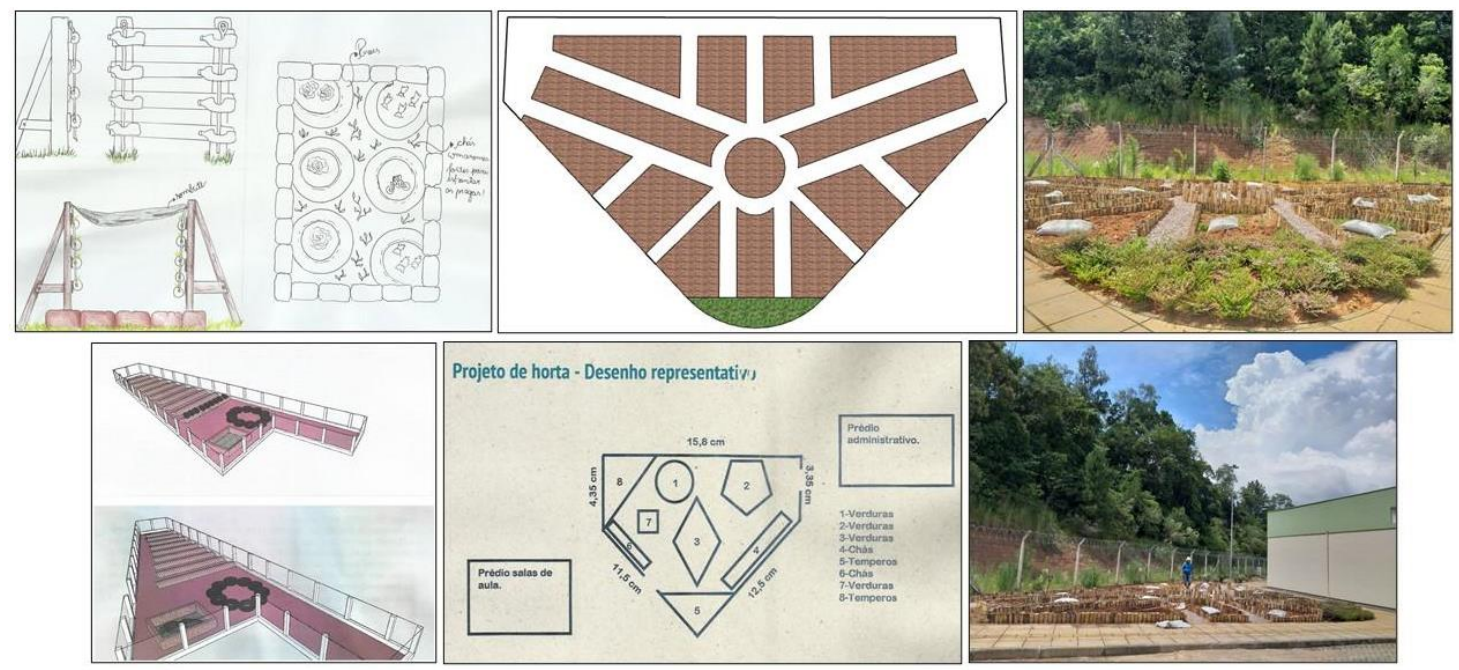

Figura 7: Modelos da horta com materiais reciclados propostos para o IFSul - Campus Lajeado. As fotografias representam a confecção da horta a partir da proposta selecionada Fonte: Elaborado pelos autores.

A partir dos resultados da análise, a EMATER emitiu as orientações para a melhor adubação indicada para a correção do solo, visando a incorporação dos nutrientes para torná-lo mais fértil. Ainda, no sentido do correto uso do solo e reaproveitamento de material orgânico, a EMATER sugeriu a utilização do húmus líquido, como uma opção para a adubação orgânica em hortaliças, sendo obtido pela mistura de húmus sólido e água. Diante disso, uma composteira foi pensada e construída, a partir de caixas plásticas, EVA, torneira plástica de bebedouro, telha de material reciclado, cujo funcionamento está baseado no processo descrito por Massukado (2016). A compostagem é um processo biológico de decomposição de matéria orgânica controlado, na presença de oxigênio, no qual microrganismos transformam a matéria orgânica em composto que servirá de adubo natural, rico em nutrientes.

Escolheu-se construir uma composteira vertical com minhocas, conhecida como composteira doméstica (COMPOSTA SÃO PAULO, 2014). Esse tipo de composteira permite fácil manuseio, tanto para inserir os resíduos quanto para retirar o vermicomposto e o chorume. A montagem da composteira 
vertical foi realizada com caixas ${ }^{7}$ de PVC empilhadas, sendo a primeira delas, situada na parte inferior, a contar com uma torneira para extração do chorume. Juntamente com os alimentos, foi necessário colocar matéria vegetal seca como folhas, grama e serragem para controlar a umidade e impedir o mau cheiro, o aparecimento de moscas e, consequentemente, de larvas. Foram realizados diversos furos na parte inferior das duas caixas que se localizam acima da caixa com a torneira para permitir que a parte líquida (chorume) desça para a primeira caixa, para ser posteriormente coletado através da torneira, e para a passagem das minhocas de um reservatório para o outro. Com a composteira, consegue-se produzir tanto o adubo sólido como o líquido. A construção de uma horta e da composteira permitem a interação entre a teoria e a prática de forma interdisciplinar. A partir das práticas de plantio que são desenvolvidas, possibilita-se que o estudante lide com a terra, aprenda a utilizá-la de maneira adequada e o período certo para cada plantio, oportunizando a eles o cultivo para seu próprio consumo. Dentro dessa perspectiva, criou-se um cronograma e um calendário agrícola, primando pela qualidade e produtividade, incentivando toda a comunidade do Instituto a uma alimentação saudável, sem o uso de agrotóxico e ao trabalho colaborativo.

\section{Comunicação científica: $O$ saber além da instituição}

Além do aprendizado interno da comunidade escolar, preocupou-se também, através deste projeto, levar os resultados e informações para o meio científico por meio da apresentação de trabalhos em eventos. A primeira participação foi na VII Mostra Venâncio-Airense de Cultura e Inovação MOVACl no ano de 2018. No ano seguinte, 2019, participou-se de dois grandes eventos no Estado, com a apresentação de trabalhos elaborados por estudantes do ensino fundamental, médio, educação profissional de nível técnico, superior e de pós-graduação: (a) $13^{\circ}$ Mostra de Ciência e Tecnologia MOCITEC em Charqueadas/RS, que acontece anualmente no IFSul Campus Charqueadas e (b) X FECIC 2019 - Feira de Ciências do Instituto Federal Sulrio-grandense, Campus Camaquã. Em ambos os eventos foi conquistado o prêmio de $1^{\circ}$ Lugar na Categoria Meio Ambiente.

\section{Considerações finais}

Diante do exposto, ao longo deste trabalho, conclui-se que somente a partir da conscientização de cada indivíduo pode-se desenvolver uma cultura ambiental e sustentável, em que a qualidade de vida pode prevalecer, não somente sobre os ganhos econômicos, mas, também, pelos ganhos ambientais e sociais, garantindo o futuro para a atual e futura geração. A maioria das pessoas não têm consciência dos impactos que produzem sobre o meio ambiente em decorrência de suas atividades rotineiras e nem como pequenos

\footnotetext{
7 Para a construção da composteira doméstica, com minhocas, é necessário no mínimo 3 caixas: uma para a coleta de chorume (inferior), uma para a cura da compostagem (no meio) e outra para o depósito de novos resíduos (superior).
}

Revista brasileira educação ambiental 
gestos, se feitos por uma grande parte da comunidade, podem fazer a diferença. As mudanças nos hábitos e comportamentos de consumo da comunidade acadêmica podem impactar diretamente na preservação dos recursos naturais da cidade e região e, se forem verdadeiramente incorporados pelos indivíduos, serão colocados em prática ao longo de suas vidas.

\section{Referências}

BRASIL. Lei $\mathbf{n}^{\circ} \mathbf{1 1 . 8 9 2}$ de 29 de dezembro de 2008. Institui a Rede Federal de Educação Profissional, Científica e Tecnológica, cria os Institutos Federais de Educação, Ciência e Tecnologia, e dá outras providências Disponível em: $<$ http://www.planalto.gov.br/ccivil 03/ ato2007-2010/2008/lei/l11892.htm>. Acesso em: 20 abr. 2020.

BRASIL. Decreto no 4281, de 25 de junho de 2002. Regulamenta a Lei no 9.795, de 27 de abril de 1999, que institui a Política Nacional de Educação Ambiental, e dá outras providências. Disponível em: $<$ https://www.planalto.gov.br/ccivil 03/decreto/2002/d4281.htm>. Acesso em: 22 abr. 2020.

BRASIL, Lei no 12.305, de 02 de agosto de 2010. Institui a Política Nacional de Resíduos Sólidos; altera a Lei no 9.605, de 12 de fevereiro de 1998; e dá outras providências. Disponível em: <http://www.planalto.gov.br/ccivil 03/ ato2007-2010/2010/lei/l12305.htm>. Acesso em: 05 mar 2019.

BRASIL. Ministério da Educação. Base Nacional Comum Curricular. Disponível em: $<$ http://basenacionalcomum.mec.gov.br/images/BNCC EI EF 110518 versaofi nal site.pdf >. Acesso em: 05 fev. 2020.

CARVALHO, I. C. M. Educação Ambiental crítica: nomes e endereçamentos da educação. In: Identidades da Educação Ambiental brasileira. Brasília: Ministério do Meio Ambiente, 2004.

COMPOSTA SÃO PAULO. Manual de Compostagem Doméstica com Minhocas. In: Textos e conteúdos: Morada da Floresta, Edição: Blue, Design e llustração: Pixely, São Paulo, 2014.

DIAS, G. F. Educação Ambiental: princípios e práticas. 9a ed. São Paulo: Gaia, 2004.

ECO-UNIFESP. Princípio dos 3R's. Disponível em: $<$ https://dgi.unifesp.br/ecounifesp/index.php?option=com content\&view=article \&id=10\&ltemid=8 >. Acesso em: 02 ago. 2019.

FREIRE, P. Educação e Mudança. 12. ed .Rio de Janeiro: Paz e Terra, 1983.

IFSUL. Plano de Desenvolvimento Institucional agosto de 2014 a abril de 2020. Disponível em <http://www.ifsul.edu.br/plano-de-desenv-institucional $>$. Acesso em: 22 abr. 2020. 
IFSUL. Regulamento do Nugai - Atualizado em 9 de dezembro de 2015. Disponível em: <http://www.ifsul.edu.br/sustentavel-ifsul/2016-06-01-20-3236/item/197-documentos-nugai >. Acesso em: 06 mai. 2020.

JACOBI, P. Educação Ambiental, cidadania e sustentabilidade. Cad. Pesqui., São Paulo, n. 118, mar. 2003.

KONRAD, O.; CASARIL, C.E.; SCHMITZ, M. Estudo dos resíduos sólidos domésticos de Lajeado/RS pela caracterização gravimétrica. Revista Destaques Acadêmicos, Ano 2, N. 4, 2010.

MACHADO, S. Os 5 R's do Desenvolvimento Sustentável. In: Feel Good. [post]: 30 ago. 2018. Disponível em: <https://theminimalmag.com/os-5-r-dodesenvolvimento-sustentavel/>. Acesso em: 02 ago. 2019.

MASSUKADO, L. M. Compostagem: nada se cria, nada se perde; tudo se transforma. 1. ed. Brasília: Editora IFB, 2016.

NORMA BRASILEIRA ABNT NBR 10004, Resíduos sólidos - Classificação, Segunda edição 31.05.2004. Disponível em: <http://www.vigilanciasanitaria.sc.gov.br/index.php/download/category/64legislacao?download=433:nbr-10004>. Acesso em: 01 jul de 2019.

ONU. Transformando Nosso Mundo: A Agenda 2030 para o Desenvolvimento Sustentável. Disponível em: <https://nacoesunidas.org/pos2015/agenda2030/>. Acesso em: 3 mar. 2019.

ONU. ONU Meio Ambiente promove ações de combate à poluição do ar em todo o Brasil. Disponível em: <https://nacoesunidas.org/onu-meioambiente-promove-acoes-de-combate-a-poluicao-do-ar-em-todo-o-brasil/>.

Acesso: 26 abr. 2020.

POMBO, O. Práticas Interdisciplinares. Revista Sociologias, Porto Alegre, ano 8, n. 15, jan-jun 2006, p. 208 a 245.

SANTOS, V. Educação Ambiental e os 5RS In: Estratégias de Ensino Aprendizagem.

em:

$<$ https://educador.brasilescola.uol.com.br/estrategias-ensino/educacao-

ambiental-os-5-rs.htm>. Acesso em: 3 mar. 2019.

ZITZKE, V. A.; CALIXTO, P. M. Percepção dos educandos da educação profissional técnica sobre a Educação Ambiental: um estudo de caso no IFSul/CAVG. Revista Brasileira de Educação Ambiental, São Paulo, v. 14, $n^{\circ}$ 3, 2019. 